\title{
The Effects of Clam Exercise on the Trunk Control and Balance of Stroke Patients
}

\author{
Jin Park \\ Department of Physical Therapy, Drim Sol Hospital, Jeonju, Republic of Korea
}

Purpose: The purpose of this study was to verify the effect of applying clam exercise on improving trunk control and balance ability in stroke patients. Based on this, we tried to provide clinical information.

Methods: In this study, 18 patients with chronic stroke were recruited from a rehabilitation hospital. The patients were divided into two groups: a clam exercise group (9 patients) and a control group (9 patients). After 30 minutes of neuro-development therapy, they performed clam exercise or bridge exercise for 3 weeks, 5 times a week for 30 minutes. A trunk impairment scale (TIS) and a postural assessment scale for stroke patients-trunk control (PASS-TC) were performed to evaluate the subjects' ability to control trunk before and after intervention. Balance ability was measured by Balancia before and after intervention.

Results: After the training periods, area 95\% COP and weight distribution of the affected side were significantly different from the clam exercise group compared to the control group $(p<0.05)$.

Conclusion: Based on the results of this study, in can be seen that the clam exercise is effective in improving the balance ability compared to the bridge exercise. Maintaining the standing posture requires muscle strength of the hip abduction and extension, which is the result of the clam exercise selectively strengthening these muscles. Therefore, if you want to provide intervention to improve the balance of stroke patients, it is recommended to perform a clam exercise.

Keywords: Balance, Clam exercise, Stroke, Trunk control

\section{INTRODUCTION}

Stroke causes hemiplegic symptoms in which the opposite side of the brain is affected, causing abnormal movement, coordination, and control problems owing to loss of perceptual and cognitive functions and delaying the recovery of long-term motor skills. ${ }^{1,2}$ The delay in recovery of motor ability causes asymmetric postures of the affected and unaffected sides, making it difficult to maintain an independent standing posture..$^{3-5}$ This requires a reaction to adjust posture to external stimuli in various environments, but causes problems in living a daily life owing to a decrease in balance ability. ${ }^{6}$

The balance ability of stroke patients should be harmonized with sensory such as visual, vestibular, and somatosensory, and musculoskeletal system such as muscle strength, muscle tension, and flexibility. ${ }^{7.8}$ In particular, the trunk control ability is important because it is central to the

Received Nov 17, 2020 Revised Dec 16, 2020

Accepted Dec 18, 2020

Corresponding author Jin Park

E-mail mnipj1119@gmail.com movements of the upper and lower extremities. In addition, trunk control and balance ability are important factors for functional movement in various environments. ${ }^{910}$ In clinical practice, to improve the trunk control ability in stroke patients, exercises are performed to strengthen the trunk muscles in various postures. ${ }^{11-14}$ Among them, the bridge exercise proven to be effective for the balance ability by eliciting the activity of the abdominal muscles involved in trunk control and improving the muscle strength of the trunk muscles. ${ }^{15,16}$ However, stroke patients have limited abdominal muscle contraction owing to their asymmetric posture. ${ }^{17}$

In order to improve this point, it is possible to apply the clam exercise that can improve the trunk control ability and lead to selective strengthening of the abductor and extensor hip joints. Clam exercise is a movement that allows the trunk, pelvis, and legs to be aligned in a sidelying position, bends the hip joint $45^{\circ}$, bends the knee joint $90^{\circ}$ and involves hip abduction $20^{\circ}{ }^{18}$ Willcox and Burden ${ }^{19}$ reported that by performing clam exer-

Copylight (C)2020 The Korean Society of Physical Therapy

This is an Open Access article distribute under the terms of the Creative Commons Attribution Non-commercial License (https:// creativecommons.org/license/by-nc/4.0.) which permits unrestricted non-commercial use, distribution, and reproduction in any medium, provided the original work is properly cited. 
cise in general adults, muscle activity of the abdominal and hip abduction and extension muscles involved in balance ability improved. Koh et al. ${ }^{20}$ reported that muscle activity of the hip extensor and abdominal muscles improved by applying clam exercise to patients with low back pain. A study by Chan et al. ${ }^{21}$ also reported that clam exercise applied to young adults can elicit activity of the abdominal muscles. Through this, it was verified that the application of clam exercise is an effective method to improve the activity of the abdominal and lower extremities involved in balance. In addition, since it is possible to selectively contraction of the hip abductor and extensor through the clam exercise, it can reduce the compensation effect in the trunk, so it is an effective exercise method for subjects who have a compensation effect in the trunk due to weakness of hip muscles, such as a stroke patient.

However, previous studies have conducted clam exercise for the general public to verify only the improvement in muscle activity of the abdominal muscles and hip joints. Few studies have verified the effectiveness of clam exercise in subjects with reduced trunk control and balance ability, such as in stroke patients. The bridge exercise is often performed in clinical practice, but due to the asymmetric posture and compensatory action, the trunk control ability and selective strengthening of the hip joint muscles on the affected side are limited. Therefore, in this study, the clam exercise was performed on stroke patients to verify the effect on the trunk control ability and balance ability, and to provide clinical information based on this.

\section{METHOD}

\section{Subjects}

Among stroke patients receiving rehabilitation exercise therapy at Jeonju D Rehabilitation Hospital, 20 subjects who agreed to understand the purpose of the study and agreed to participate in the study were conducted after obtaining consent from the Helsinki Declaration. Two of them were eliminated from the study subject due to discharge and pain, and the study was conducted with a total of 18 subjects. The selection criteria of the study subjects were as follows. A person who is 6 months or older and less than 2 years after the onset of stroke, who has a Korean version of mini-mental state examination (K-MMSE) score of 24 or higher, and can follow the therapist's instructions, who were able to stand up independently, those who did not have vision and hearing impairments, and who had a score of 3 or higher for the manual abduction muscles of the hip and extension muscles of the hip. Those with neurological disorders other
Table 1. General characteristics of subjects

\begin{tabular}{lcc}
\hline & CE group $(\mathrm{n}=9)$ & Control group $(\mathrm{n}=9)$ \\
\hline Age $(\mathrm{yr})$ & $53.6 \pm 9.2$ & $51.9 \pm 10$ \\
Gender (M/F) & $7 / 2$ & $7 / 2$ \\
Time since stroke (month) & $11.2 \pm 3.8$ & $11.4 \pm 3.9$ \\
Type of lesion & & \\
Hemorrhagic & 7 & 2 \\
Infarction & 2 & 7 \\
Side of lesion (Rt/Lt) & $2 / 7$ & $4 / 5$ \\
Height (cm) & $169.7 \pm 9.9$ & $168.2 \pm 9.7$ \\
Weight (kg) & $63.9 \pm 15.4$ & $64.1 \pm 7.3$ \\
FMLE (score) & $24.2 \pm 2.6$ & $23.3 \pm 2.8$ \\
\hline
\end{tabular}

Mean \pm standard deviation.

CE group: Clam exercise group, FMLE: Fugl-meyer assessment of lower extremity.

than stroke, which could affect balance, were excluded.

Subjects who participated in this study were randomly assigned to two groups, which paired subjects with similar physical abilities, by using the Berg balance scale (BBS). The clam exercise group consisted of 9 subjects (CE group) and the bridge exercise group consisted of 9 subjects (control group). Table 1 summarizes the subjects' general characteristics.

\section{Procedures}

In both groups, after 30 minutes of neuro-developmental therapy, clam exercise or bridge exercise were performed 30 minutes, 5 times a week for a total of 3 weeks, to control the trunk and strengthen the lower extremity. Before and after training, the change of trunk control and balance of the subjects was measured.

\section{1) Clam exercise}

The group who performed the clam exercise had a sidelying position on the treatment bed with the affected side facing upward. The trunk, pelvis, and legs were aligned, and the hips were bent at $45^{\circ}$ and the knees at $90^{\circ}$, and both heels were placed together. After this, the target bar was installed to open the knee of the affected leg located on the upper side so that the hip abduction angle was $20^{\circ}$, and it was possible to keep the height constant from touching the knee. It was maintained for 5 seconds in an abduction state, and repeated 10 times, with rest for 1 minute to minimize muscle fatigue. At this time, the elastic bands were connected between the femurs and the strength of the hip abduction muscles was strengthened, and resistance was gradually increased by applying yellow, red, and green colors for each week. The therapist provided instructions to avoid body collapse from the side (Figure 1A). 

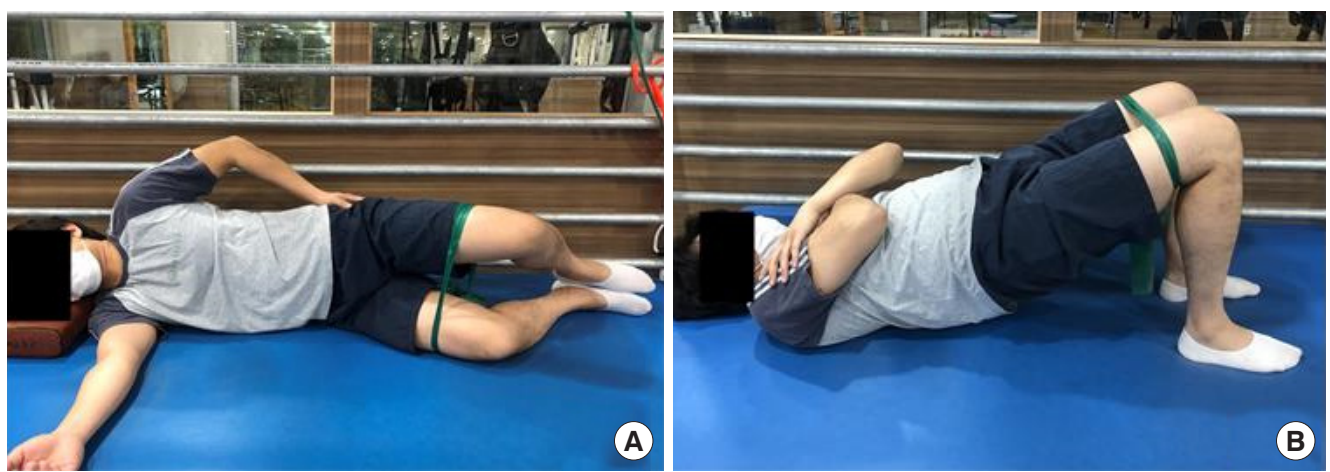

Figure 1. Exercise program. (A) Clam exercise, (B) Bridge exercise.

\section{2) Bridge exercise}

Subjects were asked to supine position on the treatment bed. In order to prevent pressing the ground with both hands, it was placed on the chest. After flexing the hips $60^{\circ}$ and the knees $90^{\circ}$, the lower limbs were separated by shoulder width. The pelvis was lifted so that the angle of the hip joint was $0^{\circ}$ and maintained for 5 seconds, repeated 10 times, and rested for 1 minute to minimize muscle fatigue. At this time, the elastic band was used to connect between the femurs and maintain the power of hip abduction, and resistance was gradually increased by applying yellow, red, and green colors for each week. The therapist instructed the body not to collapse from the side (Figure 1B).

\section{Assessment}

\section{1) Trunk control}

A trunk impairment scale (TIS) and a postural assessment scale for stroke patients-trunk control (PASS-TC) were performed to evaluate the subjects' ability to control trunk before and after intervention. The trunk impairment scale is a method for evaluating disorders in stroke patients and has proven reliability and validity. ${ }^{22}$ It consists of three items: static sitting posture item, dynamic sitting posture item, and coordination evaluation item. This scale consists of a minimum of 0 points and a maximum of 23 points The higher the score, the better the trunk control ability. Postural assessment scale for stroke patients-trunk control is a method for evaluating the balance of stroke patients and posture control ability of the trunk. It is performed in three postures: lying down, standing, standing, and the higher the score, the better the trunk control ability. This scale consists of a total of 15 points, with a minimum of 0 points and a maximum of 3 points per item.

\section{2) Balance}

The balance ability measurement equipment (Balancia software, Mintosys, Korea) was used to analyze the balance ability of the subjects. This equipment is analyzed by collecting information on the center of pressure (COP) of the subject while providing it to the computer program (Balancia software) via Bluetooth while the subject is standing on the Wii balance board. The variables used in this study are the velocity average of the moving distance of the COP divided by the time, the path length of the moving distance of the COP, and the area 95\% COP area formed in the shape of an ellipse around the center and weight distribution of the affected side.

Subjects took off their shoes, climbed on a pressure plate, put their arms down and measured in a comfortable standing position. The measurement was conducted in 1 minute, and the average value was used by repeating the measurement 3 times. Researchers assisted at close range to prevent falls during the measurement.

\section{Statistical analysis}

All statistical analyzes of this study were conducted using the Korean version of SPSS 22.0 (SPSS Inc., Chicago, IL, USA), and a normality test was performed by KolmogorovSmirnov test. To examine the differences in general and the medical characteristics between the two groups, the independent t-test were used. The Wilcoxon matched-pairs signed-ranks test was conducted to examine the changes in the TIS and the PASS-TC in each group. In addition, a paired ttest was conducted to examine the changes before and after the balance ability of each group. The MannWhitney $\mathrm{U}$ test was conducted to examine the difference in the amount of change between the groups in the TIS and the PASS-TC. In order to investigate the difference in the amount of change in balance ability between groups, the pre-intervention value was set as a covariate and analysis of covariance was performed. The significance level was 0.05 . 
Table 2. Comparison of pre and post training outcome measures of trunk control ability within and between groups

\begin{tabular}{lccc}
\hline & CE group $(n=9)$ & Control group $(n=9)$ & $p$ \\
\hline TIS (score) & & & \\
Pre & $13.56 \pm 4.67$ & $15.67 \pm 3.77$ & 0.15 \\
Post & $15.78 \pm 4.52$ & $17.00 \pm 3.28$ & \\
p & $0.01^{*}$ & $0.02^{*}$ & \\
PASS-TC (score) & & & \\
Pre & $11.44 \pm 2.07$ & $11.89 \pm 1.62$ & 0.11 \\
Post & $13.33 \pm 1.32$ & $12.78 \pm 1.30$ & \\
$p$ & $0.02^{*}$ & $0.04^{*}$ & \\
\hline
\end{tabular}

Mean \pm standard deviation.

CE group: clam exercise group, TIS: Trunk Impairment scale, PASS-TC: Postural assessment scale for stroke patients-trunk control, significant difference between pre and post intervention within the group.

${ }^{*} p<0.05$.

\section{RESULTS}

\section{General characteristics}

There was no statistical difference between groups for general characteristics $(\mathrm{p}>0.05)($ Table 1$)$

\section{Trunk control}

Among the trunk control, the results of a comparison before and after the training showed that both group's TIS and PASS-TC statistically significantly increased $(\mathrm{p}<0.05)$. After the training, no statistically significant differences were observed between the two groups $(\mathrm{p}>0.05)$ (Table 2).

\section{Balance}

The results of a comparison before and after the training showed that both group's velocity average, path length, area 95\% COP statistically significantly decreased $(\mathrm{p}<0.05)$. The weight distribution of the affected side significantly increased after intervention only in the CE group $(\mathrm{p}<0.05)$. After the training, the results of a comparison between the two groups showed that the CE group's area 95\% COP and weight distribution of the affected side statistically significantly difference compared to the control group $(\mathrm{p}<0.05)($ Table 3$)$.

\section{DISCUSSION}

This study was conducted to verify the effect of performing clam exercise to improve the trunk control and balance ability of stroke patients and to provide clinical information based on this.

The TIS and PASS-TC, which were used to investigate changes in trunk
Table 3. Comparison of pre and post training outcome measures of balance ability within and between groups

\begin{tabular}{lccc}
\hline & CE group $(\mathrm{n}=9)$ & Control group $(\mathrm{n}=9)$ & $\mathrm{p}$ \\
\hline Velocity average $(\mathrm{cm} / \mathrm{s})$ & & & \\
Pre & $2.71 \pm 0.48$ & $2.58 \pm 0.52$ & 0.95 \\
Post & $2.54 \pm 0.55$ & $2.39 \pm 0.66$ & \\
$\mathrm{p}$ & $0.03^{*}$ & $0.02^{*}$ & \\
Path length $(\mathrm{cm})$ & & & \\
Pre & $81.22 \pm 14.41$ & $77.32 \pm 15.68$ & 0.75 \\
Post & $76.29 \pm 16.64$ & $71.16 \pm 18.30$ & \\
$\mathrm{p}$ & $0.03^{*}$ & $0.01^{*}$ & \\
Area 95\% COP $\left(\mathrm{cm}^{2}\right)$ & & & \\
Pre & $4.35 \pm 2.45$ & $3.16 \pm 1.16$ & $0.04^{+}$ \\
Post & $2.11 \pm 1.35$ & $2.34 \pm 1.13$ & \\
p & $<0.001^{*}$ & $0.04^{*}$ & \\
Weight distribution $(\%)$ & & & \\
Affected & & & \\
$\quad$ Pre & $45.92 \pm 1.84$ & $46.85 \pm 2.54$ & $0.01^{+}$ \\
Post & $48.74 \pm 1.47$ & $47.49 \pm 1.38$ & \\
p & $<0.001^{*}$ & 0.34 & \\
\hline
\end{tabular}

Mean \pm standard deviation.

CE group: Clam exercise group, significant difference between pre and post intervention within the group, significant difference between the change values among the groups.

${ }^{*} p<0.05,{ }^{p} p<0.05$

control ability, showed statistically significant improvement after intervention in both groups. Thus trunk control ability can be effectively improved by performing clam and bridge exercises. Chan et al. ${ }^{21}$ reported that when clam exercise was performed, core muscle activity and hip extensor and abductor activity improved. A study by Koh et al. ${ }^{20}$ also verified that the activity of the abdominal and lower extremity muscles improved with clam exercise. In particular, the activities of the abductor and extensor muscles of the hip joint are related to the stability of the trunk, which is a result of the improvement of the core muscle activity to secure the stability of the trunk during the activities of the hip abductor and extensor muscles through clam exercise. ${ }^{23}$ During clam exercise, when the affected lower limb moves, activity of the abdominal muscle occurs to limit abnormal pelvic rotation, and based on this, it is thought that the trunk control ability improves after clam exercise. Bridge exercise is an exercise to improve muscle contraction of lower extremity muscles involved in stabilization of the body against gravity. Lehman et al. ${ }^{24}$ adopted mobilization of lower extremity muscles involved in trunk stability through bridge exercise. It was verified that it is an effective method for muscle activity. In this study, it was found that the trunk control ability improved after the intervention in the group that performed bridge exercise. This is thought to be the result of the improvement in the activity of the muscles involved in 
trunk stabilization.

As a result of measuring the balance ability, the velocity average and area 95\% COP were statistically significantly decreased after intervention in both groups. This indicates that both groups are effective methods for improving balance ability after intervention compared to before intervention. In order to adjust balance, harmony of the nerve sensory system and musculoskeletal system is required. In particular, muscle strength and trunk control ability are important factors in balance control. ${ }^{8}$ In this study, it was found that both clam and bridge exercises improve trunk control ability after intervention. Based on these results, both groups were considered to show improved balance ability with trunk ability improvement after the intervention.

As a result of comparing the weight distribution of the affected side, only the CE group showed improved results after intervention. This means that clam exercise is an effective way to improve the weight distribution of the affected side. It was reported that clam exercise among stroke patients was effective in improving the strength of the hip abduction and extension muscles of the lower extremities. ${ }^{25}$ Chan et al. ${ }^{26}$ reported that the lower gluteus maximus can be strengthened through clam exercise. The main role of the lower gluteus maximus is external rotation, but it is reported that it can selectively strengthen the hip extensor because it contains a larger moment arm for hip extension. Therefore, the clam exercise is an effective exercise method for selective activation of the abduction and extension muscles of the hip joint. The hip abduction and extension muscles are important factors in maintaining a static standing posture. In particular, it is necessary to improve muscle strength in order to increase weight distribution to the affected side. In this study, it is thought that the results of improving the muscle strength of the abduction and extension muscles of the affected hip joint by repeatedly performing the clam exercise, and accordingly, the weight distribution of the affected side improved.

In the comparison between groups, the CE group showed the area 95\% COP reduction and an improved weight distribution of the affected side compared with the control group. It was thought that the decrease in area 95\% COP was associated with increased weight distribution on the affected side compared with the bridge exercise. Stroke patients have a high risk of falls due to asymmetric weight distribution between the affected and unaffected sides. In order to reduce the sway area, the weight distribution of the affected side is an important factor. In order to improve the weight distribution, the role of the abductor and extensor muscles of the affected hip joint is important. Because clam exercise is performed in a posture against gravity, it is an effective method to improve the muscle activity of the abductor and extensor muscles of the hip joint compared with bridge exercise performed in the supine position. ${ }^{26}$ Therefore, the results of this study are thought to be that the muscle strength of the hip abductor and extensor muscles improved through clam exercise, the weight distribution of the affected side improved, and the area 95\% COP was reduced by the improved control ability of the trunk. When performing a bridge exercise on a stroke patient, it is limited in strengthening the hip abductor and extensor muscles on the affected side because it may depend on the unaffected side. However, the clam exercise can selectively strengthen the hip abductor and extensor muscles on the affected side and reduce compensatory movement. Based on this, the weight distribution to the affected side increases, resulting in improved balance ability.

In this study, to evaluate the trunk control ability, a trunk impairment scale and postural assessment scale for stroke patients' trunk control was performed, and a balance ability measuring instrument was used to measure changes in balance ability. However, these methods were difficult to test for changes in kinematics to trunk control or balance. Both groups were treated with neuro-development therapy for 30 minutes before intervention, but there were limitations in controlling factors that may affect balance. In addition, since it was applied to some stroke patients admitted to the hospital, there is a limit to generalize to all stroke patients. Therefore, in the future, it is necessary to measure the kinematics changes in trunk control ability and balance ability after intervention in more subjects.

Clam exercise to improve the trunk control and balance ability of stroke patients was found to be an effective method to reduce the sway area and improve the weight distribution of the affected side compared with bridge exercise. Therefore, in order to elicit improved results of trunk control and balance ability in stroke patients in clinical practice, it is recommended to perform clam exercise.

\section{REFERENCES}

1. Lamontagne A, De Serres SJ, Fung J et al. Stroke affects the coordination and stabilization of head, thorax and pelvic during voluntary horizontal head motions performed in walking. Clin Neurophysiol. 2005;116(1): 101-11.

2. Mercier L, Audet T, Hebert R et al. Impact of motor, cognitive, and perceptual disorders on ability to perform activities of daily living after stroke. Stroke. 2001;32(11):2602-8.

3. Januario F, Campos I, Amaral C. Rehabilitation of postural stability in ataxic/hemiplegic patients after stroke. Disabil Rehabil. 2010;32(21): 1775-9.

4. Nyberg L, Gustafson Y. Patient falls in stroke rehabilitation. a challenge to 
rehabilitation strategies. Stroke. 1995;26(5):838-42.

5. Sharp SA, Brouwer BJ. Isokinetic strength training of the hemiparetic knee: effects on function and spasticity. Arch Phys Med Rehabil. 1997;78 (11):1231-6.

6. Chen IC, Cheng PT, Chen CL et al. Effects of balance training on hemiplegic stroke patients. Chang Gung Med J. 2002;25(9):583-90.

7. Shumway-Cook A, Horak FB. Assessing the Influence of Sensory Interaction on Balance: Suggestion from the Field. Phys Ther. 1986;66(10): 1548-50

8. Horak FB. Clinical measurement of postural control in adults. Phys Ther. 1987;67(12):1881-5.

9. Van Nes IJW, Nienhuis B, Latour H et al. Posturographic assessment of sitting balance recovery in the subacute phase of stroke. Gait Posture. 2008;28(3):507-12.

10. Verheyden G, Nieuwboer A, Wit LD et al. Trunk performance after stroke: an eye catching predictor of functional outcome. J Neurol Neurosurg Psychiatry. 2007;78(7):694-8.

11. Ada L, Dean CM, Mackey FH. Increasing the amount of physical activity undertaken after stroke. Phys Ther Rev. 2006;11(2):91-100.

12. Cabanas-Valdes R, Cuchi GU, Bagur-Calafat C. Trunk training exercises approaches for improving trunk performance and functional sitting balance in patients with stroke: a systematic review. NeuroRehabilitation. 2013;33(4):575-92.

13. Kim BH, Lee SM, Bae YH et al. The effect of a task-oriented training on trunk control ability, balance and gait of stroke patients. J Phys Ther Sci. 2012;24(6):519-22.

14. Vera-Garcia FJ, Barbado D, Moya M. Trunk stabilization exercises for healthy individuals. Rev Bras Cineantropom Desempenho Hum. 2014; 16(2):200-11.

15. Chan BK, Ng SS, Ng GY. A hemo-based program of transcutaneous electrical nerve stimulation and task-releted trunk training improves trunk control in patients with stroke: a randomized controlled clinical trial. Neurorehabil Neural Repair. 2015;29(1):70-9.
16. Karthikbabu S, Nayak A, Vijayakumar K et al. Comparison of physio ball and plinth trunk exercises regimens on trunk control and functional balance in patients with acute stroke: a pilot randomized controlled trial. Clin Rehabil 2011;25(8):709-19.

17. Garcia-Vaquero MP, Moreside JM, Bronton-Gil E et al. Trunk muscle activation during stabilization exercises with single and double leg support. J Electromyogr Kinesiol. 2012;22(3):389-406.

18. Boren K, Conrey C, Le Coguic J et al. Electromyographic analysis of gluteus medius and gluteus maximus during rehabilitation exercises. Int J Sprots Phys Ther. 2011;6(3):206.

19. Willcox EL, Burden AM. The influence of varying hip angle and pelvis position on muscle recruitment patterns of the hip abductor muscles during the clam exercise. J Orthop Sports Phys Ther. 2013;43(5):325-31.

20. Koh EK, Park KN, Jung DY. Effect of feedback techniques for lower back pain on gluteus maximus and oblique abdominal muscle activity and angle of pelvic rotation during the clam exercise. Phys Ther Sport. 2016; 22:6-10.

21. Chan MK, Chow KW, Lai AY et al. The effects of therapeutic hip exercise with abdominal core activation on recruitment of the hip muscles. BMC Musculoskelet Disord. 2017;18(1):313.

22. Verheyden G, Nieuwboer A, Mertin J et al. The trunk impairment scale: a new tool to measure motor impairment of the trunk after stroke. Clin Rehabil. 2004;18(3)326-34.

23. Frank C, Page P, Lardner R. Assessment and treatment of muscle imbalance: the janda approach. Champaign, Human Kinetics, 2009;31-6.

24. Lehman GJ, Hoda W, Oliver S. Trunk muscle activity during bridging exercises on and off a swissball. Chiropr Osteopat. 2005;13(1):14.

25. Park J. The effects of clam exercise with visual feedback on the hip muscle strength of patients with chronic stroke. Int J Psychosoc Rehabil. 2020;24(6):6141-6.

26. Chan MK, Chow KW, Lai AY et al. The effects of therapeutic hip exercise with abdominal core activation on recruitment of the hip muscles. BMC Musculoskelet Disord. 2017;18(1):313. 